\title{
Türkiye'de Sanayileşme, Finansal Gelişme, Ekonomik Büyüme ve Kentleşmenin Enerji Tüketimi Üzerindeki Etkisi: Çoklu Yapısal Kırılmalı Bir Araştırma
}

\author{
Effect of Industrialization, Financial Development, Economic Growth and Urbanization \\ on Energy Consumption in Turkey: An Evidence with Multiple Structural Breaks
}

\author{
Fuat LEBE' ${ }^{1}$ Yusuf Ekrem AKBAŞ²
}

\begin{abstract}
ÖZET
Bu çalışmanın amacı, Türkiye'deki finansal gelişme, ekonomik büyüme, kentleşme ve sanayileşmenin enerji tüketimi üzerindeki etkisini araştırmaktır. Bu amaçla, Türkiye'nin 1960-2012 dönemine ait yıllık veriler kullanılmıştır. IIlk olarak, çalışmada kullanılan bu beş değişkenin birim kök içerip içermediği analiz edilmiştir. Kullanılan geleneksel birim kök testleri sonucunda seriler I(0) ve I(1)'dir. Geleneksel yöntemlere ilave olarak, çoklu yapısal kırılmalara izin veren birim kök testi de kullanılmıştır. Bu testin sonucunda tüm serilerin I(1) olduğu ve yapısal kırılma içerdiği sonucuna ulașılmıștır. Seriler arasında uzun dönem ilişkisi olup olmadığını analiz etmek için ise çoklu yapısal kırılmalara izin veren eşbütünleşme testi kullanılmıştır. Bu testin sonucunda seriler arasında uzun dönem ilişkisi olduğu ve yapısal kırılma içerdiği tespit edilmiştir. Son olarak model, DOLS ve FMOLS ile tahmin edilmiş ve SVAR modeline dayalı etki-tepki analizi yapılmıştır. Yapılan analiz sonucu, Türkiye'deki enerji tüketimi üzerinde, sırasıyla, ekonomik büyüme, sanayileşme ve finansal gelişmenin öne çıktığı tespit edilmiştir. Kentleşmenin ise fazla bir etkisinin olmadığı belirlenmiştir.
\end{abstract}

Anahtar Kelimeler: Enerji tüketimi, finansal gelişme, ekonomik büyüme, kentleşme ve sanayileşme, çoklu yapısal kırılma

\section{GíRiş}

İlk çağlardan günümüze enerji, sosyal ve ekonomik gelişmenin temel faktörlerden birisidir. Ekonomik büyüme sağlanması ve sürdürülebilmesi için enerjinin kesintisiz ve sürdürülebilir olarak temin edilmesini gerektirmektedir. Enerji tüketimini ekonomik performansla yakından ilgilidir. Gelirin ve sosyal refahın artmasına paralel olarak enerji tüketimi önemli ölçüde artmaktadır. Ekonomik büyümeyle birlikte enerjinin sermaye faktörü ile tamamlayıcılık ilişkisi içinde bulunduğu başta sanayi sektörü olmak üzere enerji tüketiminde artış görülmektedir. Bu nedenle, küresel rekabette gerek ülke sanayisinin gerekse ülke ekonomilerinin gelişerek ayakta kalması için sürdürülebilir, güvenilir ve yenilenebilir enerji

\begin{abstract}
The aim of the present study is to investigate the effect of financial development, economic growth, urbanization and industrialization on energy consumption in Turkey. For this purpose, the annual data of Turkey for the period 1960-2012 was used in the study. First, it was analyzed whether these five variables used in the study contained a unit root. As a result of the traditional unit root tests series are $\mathrm{I}(0)$ and $\mathrm{I}(1)$. In addition to traditional methods, the unit root test that allows multiple structural breaks was also used. As the result of this test, it was found that all the series were $I(1)$ and contained structural breaks. The cointegration test that allows for multiple structural breaks was used in order to analyze whether there is a long term relationship between the series. As the result of this test, it was found that there was a long term relationship between the series and the series contained structural breaks. Finally, the model was predicted through DOLS and FMOLS and an impulse-response analysis was performed based on the SVAR model. As the result of the analysis, it was determined that the effects of economic growth, industrialization and financial development were respectively prominent on the energy consumption in Turkey The effect of urbanization on energy consumption was not found to be considerable.
\end{abstract}

Keywords: Energy consumption, financial development, economic growth, urbanization and industrialization, multiple structural breaks

kaynaklarının sağlanması gerekir. Çünkü bu gelişmelerin beraberinde enerji tüketiminde artışın görülmesi kaçınılmazdır.

Literatürde, enerji tüketimini ile ekonomik büyüme arasındaki ilişkiyi konulan çok sayıda ampirik çalışma mevcuttur. Ancak, enerji tüketimi, ekonomik büyüme ve finansal gelişme arasındaki ilişki özellikle son yıllarda ampirik çalışmalara konu olduğu görülmektedir. Özellikle finansal gelişme ile ekonomik büyüme ilişkisi, teorik anlamda Bagehot (1873) ve Schumpeter (1912) tarafından ilk olarak ele aldıktan sonra, Goldsmith (1969), McKinnon (1973) ve Shaw (1973)'un çaış̧malarıyla daha geniş kapsamlı ele alınıp, tartışıımıştır. Günümüzde ise söz konusu değişkenler arasındaki ilişki farkı ülke ve bölge grupları için gerek zaman 
serisi gerek panel çalışmalarla incelenmeye ve tartışılmaya devam edilmektedir. Finansal gelişme ve ekonomik büyüme arasındaki ilişkiyi önemli kılan nokta, özellikle finansal kurumların yeteri kadar gelişmediği, düzenleme ve denetim sistemlerinin zayıf olduğu gelişmekte olan ülkelerde finansal sektörle ilgili reformlara ne ölçüde öncelik vermeleri gerektiği konusunda fikir vermeleridir. Söz konusu ilişkiyi önemli kılan bir diğer faktör, finansal piyasalardaki gelişmişlik düzeyinin, ülkelerin neden farklı oranlarda büyüdüklerine kısmen açıklık getirmesidir.

Son beş yılda ise enerji tüketimi ile finansal gelişmenin yanında sanayileşme ve kentleşme faktörlerinin de araştırmalara konu olduğu görülmektedir. Ancak, bu çalışmalar oldukça sınırlıdır (Al-mulali ve Lee, 2013; Shahbaz ve Lean, 2012). Bu çerçevede, Türkiye ekonomisini konu alan çalışmalar ise bulunmamaktadır. Bu yönüyle çalışmamız ilk niteliğindedir.

Türkiye ekonomisi, son yıllarda büyük bir yükseliş trendine girmiş ve enerji talebi de gün geçtikçe artış göstermektedir. Bu bağlamda, çalışmamızda enerji tüketimi, finansal gelişme, ekonomik büyüme, kentleşme ve sanayileşme arasındaki etkileşim Türkiye ekonomisi için araştırılmak istenmiştir. Çalışmamız beş bölümden oluşmaktadır. Giriş niteliğindeki bu bölümün ardından konuyla ilgili literatür ikinci bölümde, araştırmada kullanılacak veriler ve modellerin yapısının yer aldığı çalışmanın metodolojisi üçüncü bölümde ortaya konmuştur. Tahmin sonuçları dördüncü bölümde sunulmuştur. Beşinci bölümde ise sonuç kısmına yer verilmiştir.

\section{LITERATÜR ÖZETi}

Literatürde, enerji tüketimini konulan bir çok ampirik çalışma mevcuttur. Bu çalışmaları temelde iki gruba ayırabiliriz. Birincisi, enerji tüketimi ile ekonomik büyüme arasındaki ilişkiyi çeşitli ülke grupları için araştıran çalışmalardır. ${ }^{1}$ Ikinci gruba giren çalışmalarda ise, enerji tüketimi ile finansal gelişme arasındaki ilişkiyi ele aldıkları görülmektedir (Sadorsky, 2010, 2011; Zhang vd., 2011; Çoban ve Topcu, 2013). Bu ikincisi gruba girenler çalışmaların bazıları söz konusu değişkenlerin (enerji tüketimi ve finansal gelişme) yanında doğrudan yabancı sermaye yatııımları (FDI), sanayileşme, kentleşme ve açıklık gibi etmenlerin rolünü de araştırdıkları görülmektedir. ${ }^{2}$ Bu çaıışmaların özellikle son beş yılda yoğunluk kazandığı görülmektedir. Ancak bu çalışmalar da oldukça sınırIıdır. Mesela, Shahbaz ve Lean (2012) Tunus'un 19712008 dönemine ait verileri kullanarak enerji tüketimi, finansal gelişme, ekonomik büyüme, sanayileşme ve kentleşme arasındaki ilişkiyi araştırmışlardır. Bu amaçla, eşbütünleşme ve VECM nedensellik testleri kulla- nılmıştır. Analiz sonucunda, uzun dönemde finansal gelişme ile enerji tüketimi, finansal gelişme ile sanayileşme ve enerji tüketimi ile sanayileşme arasında çift yönlü nedensellik olduğu tespit edilmiştir. Bununla birlikte, ekonomik gelişme ve kalkınma sürecinde enerji tüketimi ile finansal gelişmenin yanında, sanayileşme ve kentleşme etmenlerinin göz ardı edilmemesi gerektiği vurgulanmıştır.

Mudakkar vd. (2013) SAARC (Güney Asya Bölgesel İşbirliği Derneği) ülkeleri için ekonomik büyüme, ilgili enerji fiyatı (REP), FDI ve finansal gelişme arasındaki ilişki araştırılmıştır. Bu amaçla, söz konusu değişkenlerin 1975-2011 dönemine ait verileri VAR yaklaşımı ile nedensellik testleriyle analiz edilmiştir. VAR analiz sonucu, enerji tüketimi, ekonomik büyüme ve finansal gelişmenin hem kısa hem de uzun dönemde FDI'yi teşvik eden en önemli belirleyiciler olduğu tespit edilmiştir. Nedensellik testi sonucu, Hindistan'da enerji tüketimi, ekonomik büyüme ve finansal gelişme FDI'yi etkileyen önemli faktörler olduğu tespit edilmiştir. Pakistan'da hem kısa hem de uzun dönemde FDI ile enerji tüketimi arasında çift yönlü nedenselliği destekleyen bulgular elde edilmiştir. Finansal gelişme ile enerji tüketimi arasında sadece kısa dönemde çift yönlü nedenselliği destekleyen bulgular ortaya konmuştur. Sri Lanka için hem kısa hem de uzun dönemde finansal gelişmeden enerji tüketimine ve enerji tüketiminden FDI'ye doğru tek yönlü nedensellik tespit edilmiştir.

Shahbaz, Khan ve Tahir (2013) enerji tüketimi, ekonomik büyüme, finansal gelişme ve ticaret açığı arasındaki ilişkiyi Çin ekonomisi için ele almışlardır. Bu amaçla, 1971-2011 dönemine ait veriler eşbütünleşme ve nedensellik testleriyle analiz edilmiştir. Analiz sonucu, enerji tüketimi, finansal gelişme, sermaye stoku ve dış ticaret açığının ekonomik büyümeyi pozitif yönde etkilediği belirlenmiştir. Nedensellik testi sonucu, finansal gelişme ile enerji tüketimi arasında çift yönlü; enerji tüketiminden ekonomik büyümeye doğru tek yönlü nedensellik olduğu tespit edilmiştir.

Islam vd. (2013) enerji tüketimi, ekonomik büyüme, finansal gelişme ve nüfus arasındaki ilişkiyi Malezya ekonomisi için araştırmışlardır. Bu amaçla, Malezya'nın 1971-2009 dönemine ait verileri eşbütünleşme ve nedensellik testleriyle analiz edilmiştir. Analiz sonucu enerji tüketiminin, hem kısa hem de uzun dönemde ekonomik büyüme ve finansal gelişmeyi etkilediği; ancak nüfus ile enerji tüketimi arasındaki ilişkinin sadece uzun dönemde söz konusu olduğu belirlenmiştir. Nedensellik testi sonucu, hem kısa hem de uzun dönemde ekonomik büyüme ile enerji tüketimi arasında çift yönlü nedensellik olduğu tespit edilmiştir. 
Al-mulali ve Lee (2013) GCC (Körfez İşbirliği Konseyi) ülkelerinin 1980-2009 dönemine ait verileri kullanılarak enerji tüketimi, finansal gelişme, ekonomik büyüme, kentleşme ve toplam ticaret arasındaki ilişki araştırılmıştır. Bu amaçla, panel eşbütünleşme ve Dinamik OLS (DOLS) testleri kullanılmıştır. DOLS sonucunda, uzun dönemde finansal gelişme, ekonomik büyüme, kentleşme ve toplam ticaret enerji tüketimi üzerinde pozitif etkisi olduğu belirlenmiştir. Nedensellik testi sonucu ise, enerji tüketimi ile ekonomik büyüme, finansal gelişme ile ekonomik büyüme arasında çift yönlü pozitif bir nedensellik olduğu belirlenmiştir. Bununla birlikte, finansal gelişmeden enerji tüketimine ve kentleşmeden enerji tüketimine doğru tek yönlü pozitif bir nedensellik olduğu tespit edilmiştir.

Khan, Khan, Zaman, Irfan ve Khatab (2014) Güney Asya'nın ekonomik büyümesini etkileyen faktörleri belirlemek amacıyla yaptıkları çalışmada, 1975-2011 dönemine ait verileri eşbütünleşme ve VECM nedensellik testleriyle analiz etmişlerdir. Analiz sonucunda, Güney Asya ülkelerinde enerji tüketimi ile ekonomik büyüme ve finansal gelişme arasında çift yönlü nedensellik olduğu belirlenmiştir.

Khan, Khan, Zaman ve Arif (2014) enerji tüketimi, ekonomik büyüme, FDI, ilgili enerji fiyatı (REP) ve finansal gelişme arasındaki ilişkiyi ülke gruplarının 1975-2011 dönemine ait verileri kullanarak analiz etmişlerdir. Söz konusu değişkenler arasındaki ilişki Pedroni (1999) panel eşbütünleşme testi ve SUR yaklaşımıyla ele alınmıştır. Düşük gelirli, orta gelirli, Güney Afrika, MENA ve Dünya geneli ülke grupları için yaptıkları SUR sonucu, ekonomik büyüme enerji tüketimini pozitif yönde etkilediği tespit edilmiştir. Ancak, yüksek gelirli OECD ve OECD ülkesi olmayan ülke grupları için söz konusu değişkenler arasında anlamlı bir ilişki bulunmamıştır. Bununla birlikte, düşük gelirli, orta gelirli, yüksek gelirli OECD üyesi olmayan ülkeler ile MENA ülkelerinde finansal gelişme, enerji tüketimini pozitif yönde etkileyen önemli etmen olduğu belirlenmiştir.

İkinci gruba giren çalışmaların bazıları ise enerji tüketimi ile finansal gelişme arasındaki ilişkiyi Çevresel Kuznets Eğrisi (EKC) çerçevesinde ele aldıkları görülmektedir (Pao ve Tsai, 2011; Jalil ve Feridun, 2011; Shahbaz, Solarin, Mahmood ve Arouri, 2013; Shahbaz, Hye, Tiwari ve Leitao, 2013; Shahbaz, Mutascu ve Azim, 2013; Shahbaz, Tiwari ve Nasir, 2013; Ozturk ve Acaravci, 2013; Shahbaz vd., 2014). Bu çaIışmaların ortak özelliği, ele aldıkları ülkeler veya ülke grupları için EKC hipotezinin geçerli olduğunu ortaya koymalarıdır. Bu EKC hipotezi; $\mathrm{CO}_{2}$ emisyonu belli bir gelir veya gelişmişlik düzeyine kadar gelir artışıyla bir- likte arttığı, daha sonra belli bir gelir veya gelişmişlik düzeyinden sonra $\mathrm{CO}_{2}$ emisyonunun azaldığı anlamına gelmektedir. Yani, söz konusu değişkenler arasında ters-U şeklinde bir ilişki olduğu savunulmaktadır.

\section{METODOLOJI}

Bu bölümde çalışmada kullanılan değişkenler, gerekli olan veri ve manipülasyon yöntemleri ortaya konulacaktır. Ayrıca analizde kullanılacak olan yöntemler hakkında bilgiler verilecektir.

\subsection{Veri ve Kaynaklar}

Bu çalışmada, finansal gelişme (FD), ekonomik büyüme (GDP), kentleşme (UR) ve sanayileşmenin (IND) enerji tüketimi (EC) üzerindeki etkisi Türkiye ekonomisi için analiz edilmiştir. Türkiye ekonomisinde enerji tüketimi ile kentleşme verileri yıllık bazda mevcut olduğundan, çalışmamızda yıllık veriler kullanılmıştır. Söz konusu değişkenlerin 1960 öncesi verileri mevcut olmadığından çalışmamız 1970-2011 dönemiyle sınırlı kalmıştır. Bu açıklamaların ışığında, çalışmamızda kullanılacak değişkenler ve kaynakları Tablo 1'de verilmektedir.

Tablo 1: Değişkenler ve Kaynakları

\begin{tabular}{|c|l|c|}
\hline Değişkenler & \multicolumn{1}{|c|}{ Değişkenlerin Açıklaması } & Kaynaklar \\
\hline EC & $\begin{array}{l}\text { Kişi başı enerji tüketimi, kg petrol } \\
\text { eşdeğeri }\end{array}$ & WB \\
\hline GDP & $\begin{array}{l}\text { Reel kişi başı GSYiH, 2005 yılı } \\
\text { fiyatlarıyla, \$ }\end{array}$ & WB \\
\hline FD & $\begin{array}{l}\text { Finansal gelişme (Özel sektöre } \\
\text { yönelik yurtiçi krediler/GSYiH) }\end{array}$ & WB \\
\hline UR & $\begin{array}{l}\text { Kentleşme (Kent nüfusu/Toplam } \\
\text { nüfus) }\end{array}$ & WB \\
\hline IND & $\begin{array}{l}\text { Sanayileşme (Sanayi sektörünün } \\
\text { sağladığı katma değer/GSYiH) }\end{array}$ & WB \\
\hline
\end{tabular}

Tablo 1'de görüldüğü gibi, tüm veriler Dünya Bankası (WB) elektronik veri tabanından elde edilmiştir.

\subsection{Kullanılan Yöntemler}

Bu kısımda öncelikle yapısal kırılmaları dikkate alan Kapetanios (2002) birim kök testi, Maki (2012) eşbütünleşme testi ve model tahmincileri olan DOLS (Dinamik En Küçük Kareler) ile FMOLS (Tam Değiştirilmiş En Küçük Kareler) tahmincileri hakkında bilgi verilecektir. Son olarak, SVAR (Yapısal Vektör Otoregresif) model hakkında açıklamalara yer verilecektir.

\subsubsection{Kapatenios (2002) Birim Kök Testi}

Kapetanios (2002), Zivot ve Andrews (1992)'in tek kırılmaya ve Lumsdaine ve Papell (1997)'ın ise çift kırılmaya izin veren testleri geliştirerek, çoklu yapısal kırılmaya izin veren bir birim kök testini geliştirmiştir. Bu test, sıfır hipotezi altında birim kök olduğunu $\left(H_{0}\right.$ : $a=1$ ), alternatif hipotezde ise $m$ kırılmalı durağanlık hipotezini $\left(H_{1}: \alpha<1\right)$ sınamaktadır. Bu testte kullanılan 
model şu şekildedir:

$$
\begin{gathered}
y_{t}=\mu_{0}+\mu_{1} t+\alpha y_{t-1}+\sum_{i=1}^{p} \delta_{i} \Delta y_{t-i}+ \\
\sum_{i=1}^{m} \phi_{i} D U_{i, t}+\sum_{i=1}^{m} \varphi_{i} D T_{i, t}+e_{t}
\end{gathered}
$$

Burada, $\left(\Delta y_{t-1}, \ldots \ldots, \Delta y_{t-k}\right)$ kovaryans matris vektörünü ifade etmektedir. $D U_{i, t}$ ve $D T_{i, t}$ sabit ve trend için kırılma kukla değişkenlerini ifade etmektedir. Kukla değişkenler sırasıyla aşağıdaki gibi tanımlanır:

$$
\begin{aligned}
& D U_{i, t}\left\{\begin{array}{c}
1 \quad t>\text { TBiken } \\
0 \quad \text { diger durumlarda }
\end{array}\right. \\
& D T_{i, t}\left\{\begin{array}{c}
t-T B \quad t>T B \\
0 \text { diger durumlarda }
\end{array}\right.
\end{aligned}
$$

Buradaki $t$, içerisinde bulunulan tarihi, $T B$ ise yapısal kırılmanın gerçekleştiği tarihi temsil etmektedir. Kapetanios, kırılmaları tespit etmek amacıyla Bai ve Perron (1998) tarafından geliştirilen ardışık yapısal kırılma yönteminin kullanılmasını önermiştir. Hesaplanan $t$ istatistiği, ele alınan $m$ sayıda kırılma için sıfır hipotezinin testinde kullanılan örneğin tüm olası parçaları için elde edilir. Tüm olası parçalarını, tüm $t$ istatistik setlerini ise ile gösterilir. İlk kırılma tarihini bulmak için, m sayıda kırılma arasından hata (kalıntı) kareleri toplamını minimize eden tarih seçilir. Şöyle ki:

$$
\begin{aligned}
& K K T=\sum_{t=k+2}^{T}\left(y_{t}-\hat{\mu}_{0}-\hat{\mu}_{1} t+\hat{\alpha} y_{t-1}+\right. \\
& \left.\sum_{i=1}^{p} \hat{\delta}_{i} \Delta y_{t-i}+\hat{\phi}_{1} D U_{1, t}+\hat{\varphi}_{1} D T_{1, t}\right)^{2}
\end{aligned}
$$

İlk kırılma tahmin edildikten sonra bir sonraki kırılma, sonraki alt örneklerdeki tüm olası parçalarda aranır. Tüm olası parça setlerini , tüm olası parçalardaki temel hipotezi test etmek için kullanılan $\mathrm{t}$ istatistik setlerini de ile gösterelim. Daha sonra elde etmek için'e ilave edilir. Bir sonraki yapısal kırılma tarihi, minimum KKT yi veren tarih olarak seçilir. Önceki iki adım, $\mathrm{m}$ kırılma tarihi tahmin edilene kadar devam ettirilir. Tüm olası parça setlerini $T_{i}^{\alpha} \quad i=3, \ldots, \mathrm{m}$ ile gösterelim. Kullanılacak test istatistiği, ..... üzerindeki minimum test istatistiği ('dir (Kapetanios, 2002: 4-7).

\subsubsection{Maki Eşbütünleşme Testi}

Makroekonomik değişkenlerin birçoğu düzey değerinde durağan değildir. Durağan olmayan zaman serileriyle yapılan regresyon analizlerinin anlamlı olabilmesi ve gerçek ilişkileri yansıtabilmesi, ancak bu zaman serileri arasında bir eş bütünleşme ilişkisinin varlığıyla mümkün olmaktadır (Gujarati, 1999: 725726).
Eğer, seriler arasında bir eş bütünleşme ilişkisi varsa, düzey değerleriyle yapılacak analizde, bir sahte regresyon problemiyle karşılaşılmayacaktır. Ancak, uzun dönemde birlikte hareket eden değişkenlerin, dinamik davranışları denge ilişkisinden bazı sapmalar gösterebilir Bu, eş bütünleşik değişkenlerin temel bir özelliği olup, kısa dönem dinamiği üzerinde belirleyici bir rol oynar. Bu süreçle ortaya çıkan dinamik model, hata düzeltme modeli olarak adlandırılır (Enders, 1995: 365).

Analizde kullanılan serilerde yapısal kırılmaların varlığı durumunda, birim kök testlerinde olduğu gibi, seriler arasındaki uzun dönem ilişkisinin varlığını inceleyen eşbütünleşme testleri de sapmalı sonuçlar verir. Bu nedenle, eş bütünleşme testlerinde de yapısal kırılmaların etkilerinin dikkate alınması gerekmektedir (Göçer vd., 2013: 10). Maki (2012) eşbütünleşme testi, Gregory ve Hansen (1996)'in bir, Hatemi-J (2008)'nin iki yapısal kırılmayı dikkate alan testlerinden farklı olarak beş adet yapısal kırımayı dikkate almaktadır. Bu test, seriler arasındaki eşbütünleşme ilişkisini beş adet yapısal kırılmaya kadar test edebilmekte ve yapısal kırılma tarihlerini verebilmektedir. Özellikle, eşbütünleşme denkleminde üç ve daha fazla yapısal kırılma olduğunda Gregory ve Hansen (1996) ve Hatemi-J (2008) yöntemleri yetersiz kalmaktadır. Maki (2012) eşbütünleşme testi ise bu sorunu gidermektedir. Bu yöntemde analize alınacak bütün serilerin I(1) olması gerekmektedir. Bu testte sıfır hipotezi yapısal kırılmalar altında eşbütünleşme olmadığını, alternatif hipotez ise yapısal kırılmalar altında eşbütünleşme olduğunu ifade etmektedir.

Maki (2012), yapısal kırılmaların varlığı durumunda seriler arasında eşbütünleşme ilişkisi olup olmadığını test edebilmek için dört farklı model geliştirmiştir. Bu modeller;

Model 0: Sabit terimde kırılma var, trendsiz model,

$$
y_{t}=\mu+\sum_{i=1}^{k} \mu_{i} K_{i, t}+\beta x_{t}+u_{t}
$$

Model 1: Sabit terim ve eğimde kırılma var, trendsiz model,

$$
y_{t}=\mu+\sum_{i=1}^{k} \mu_{i} K_{i, t}+\beta x_{t}+\sum_{i=1}^{k} \beta_{i} x_{i} K_{i, t}+u_{t}
$$

Model 2: Sabit terim ve eğimde kırılma var, trend-

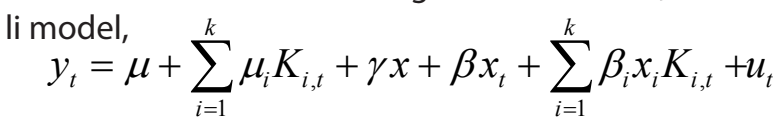

Model 3: Sabit terim, eğim ve trendde kırılma var,

$$
\begin{gathered}
y_{t}=\mu+\sum_{i=1}^{k} \mu_{i} K_{i, t}+\gamma t+\sum_{i=1}^{k} \gamma_{i} t K_{i, t}+\beta x_{t}+ \\
\sum_{i=1}^{k} \beta_{i} x_{i} K_{i, t}+u_{t}
\end{gathered}
$$


şeklindedir. Bu eşitliklerde $K_{i}$ kukla değişkenleri ifade etmekte olup, şu şekilde tanımlanmaktadır.

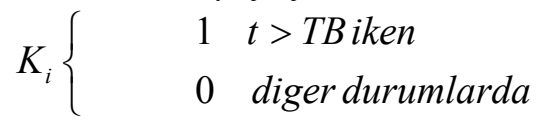

Burada, $T B$ ise yapısal kırılma tarihlerini ifade etmektedir.

\subsubsection{Eşbütünleşme Tahmincileri (OLS, FMOLS,} DOLS)

Model tahmini için En Küçük Kareler (OLS) tahmincisinin uygulanması basit olmasına rağmen, bazı sorunlara neden olabilir. Mesela OLS yönteminde, modeli oluşturan değişkenlerdeki dinamik etki dikkate alınmamaktadır. Ayrıca, OLS yöntemi küçük örnekleme sahip bir modeli tahmin etmede sapmalı sonuçlar verebilir. Bu sapmalar, $R^{2}$ nin yanlış hesaplanmasına neden olabilir. Ayrıca ikiden fazla açıklayıcı değişken olduğu zaman, birden fazla eşbütünleşme ilişkisi ya da eşbütünleşik vektör olabilir ve bu durumu iktisadi olarak açıklamak oldukça zordur. Bunun dışında OLS yönteminin parametre tahminlerini doğru yapmasına engel olan içsellik (endogeneity) sorunu olabilir. OLS yöntemine bağlı olan bu sorunlar, yeni yöntemlerin geliş̧mesine neden olmuştur (Akbaş ve Senturk, 2013: 8-9). Stock ve Watson (1993) tarafından geliştirilen DOLS bu yöntemlerden biridir. Bu yöntem OLS yönteminde meydana gelen küçük örneklem ve dinamik yapının göz ardı edilmesi sorununu ortadan kaldırmaktadır. Bu yöntem, sağlam (robust) tek denklem yaklaşımıdır ve açıklayıcı değişkenlerin bir gecikmeli değerinin ve bir sonraki değerinin alınmasıyla içsellik sorununu ortadan kaldırmaktadır. Ayrıca, bu yöntemde otokorelasyon sorunu, GLS (Genelleştirilmiş En Küçük Kareler) yöntemiyle giderilmektedir. DOLS ile model tahmini aşağıdaki (3) nolu denklem şeklinde ifade edilebilir:

$$
Y_{t}=\beta_{0}+\bar{\beta} X+\sum_{j=-q}^{\dot{p}} \bar{d}_{j} \Delta X_{t-j}+u_{t}
$$

(3) nolu denklemdeki $Y_{t}$ bağımı değişkeni, $X$ açıklayıcı değişkenlerin matrisini, $\bar{\beta}$ eş-bütünleşik vektörü, $p$ gecikme uzunluğunu (lag), $q$ ise öncül değerini (lead) ifade etmektedir.

Çalışmada kullanılan diğer bir eş-bütünleşme tahmin yöntemi FMOLS'dir. FMOLS yöntemi, eşbütünleşik regresyonların optimal tahminlerini elde etmek için Phillips ve Hansen (1990) tarafından geliştirilmiştir. FMOLS yöntemi DOLS gibi, OLS yönteminin eşbütünleşme ilişkisinden kaynaklanan içsellik sorununu ve otokorelasyon etkisini ortadan kaldırmaktadır. Buna ilave olarak, FMOLS ve DOLS yöntemleri eşbütünleşik olan değişkenlerde uzun dönem ilişkisini tahmin etmekte ve her iki yöntem açıklayıcı değişkenlerin I(1) veya I(0) olduğu durumlarda kullanılabilmektedir. FMOLS yöntemi, DOLS tahmincisinden farklı olarak gecikme sayısı (lag) ve öncül değerlere (lead) duyarlı değildir. Bununla birlikte, Pedroni (2000) çalışmasında farklı panel eşbütünleşme tahmin yöntemlerinin asimptotik özelliklerini analiz ve analiz sonucunda FMOLS yönteminin küçük örneklemlerde bile iyi sonuç verdiğini ortaya koymuştur. FMOLS yöntemiyle model tahmini ise, aşağıdaki (4) nolu denklem şeklinde oluşturulur:

$$
y_{t}=A x_{t}+u_{0 t}
$$

Burada $A, n \times m$ boyutunda matristir ve $x_{t^{\prime}}$ $m=\left(m_{1}, m_{2}\right)$ boyutunda eşbütünleşik vektörü ifade etmektedir.

\subsubsection{Yapisal VAR}

SVAR modeli, iktisat teorisine dayanarak yapısal parametreleri gelişmiş yapısal kısıtlamalarla tahmin eder. SVAR, farklı değişkenler arasındaki etkileşime izin vererek yapısal şokları belirlemeye olanak verir. SVAR modelinde her bir değişken içsel olarak ele alınmaktadır. Kovaryans matrisini kısaltmak için Cholesky faktorizasyonu kullanılmaktadır. SVAR modeli aşağıdaki (5) nolu denklem şeklinde yazılabilir (Holtemöller, 2002: 8-12).

$$
A y_{t}=B(L) y_{t-1}+C \varepsilon_{t}
$$

(5) nolu denklemdeki $A$, içsel değişkenlerin yapısal parametrelerini içermektedir. $B(L)$, modelde kullanılan gecikme sayısını ifade eden gecikme operatöründe (L) a. dereceden matris polinomudur. C, değişkenlerin şoklara eş zamanlı tepkisini göstermektedir. Bununla birlikte $y_{t}$ içsel değişkenlerin vektörünü, $y_{t-1}$ bunların gecikmeli değerinin vektörünü, $\varepsilon_{t}$ ise beyaz gürültülü olan hata terimini ifade etmektedir.

Standart VAR modelini elde etmek için sadeleştirilmiş modelde aşağıdaki (6) nolu denklem şeklinde yazmak mümkündür.

$$
y_{t}=D(L) y_{t-1}+\varepsilon_{t}
$$

Denklem (6)'daki $D(L), A^{-1} B(L)^{\prime} y i$; $e_{t}$ ise $A^{-1} C \varepsilon^{\prime} y i$ temsil eder. $e_{t}$ ilişkisiz şokların $\left(\varepsilon_{t}\right)$ lineer kombinasyonudur. Bunun aksine şokların sürekli olduğu durumda, etki-tepki fonksiyonlarındaki uzun dönem çarpanları üzerinde uygulanan kısıtlar etkilenir (McCoy, 1997: 8).

Uzun dönem kısıtlar, yapısal şokların içsel değişkenleri kümülatif bir şekilde etkilemesini engeller. Kısıtlar A ve C'de olan eş zamanlı elementlere, şokların değişkenler üzerinde geçici etkiye sahip olduğu zaman da uygulanır. Uzun dönem kısıtların uygulanması için ilave hesaplamalar gereklidir. Uzun dönem çarpanları (7) nolu denklemdeki hareketli ortalama yönteminden türetilebilir:

$y_{t}=[I-D(L) L]^{-1} \varepsilon_{t}=[I-D(L) L]^{-1} A^{-1} C \varepsilon_{t}=\mu(L) \varepsilon_{t}$ 
Denklem (7)'deki her bir $\mu_{i}$ 'nin şoklardaki değişikliklerin etkilerini gösterdiği $\mu(L)=\sum_{i=0}^{\infty} \mu_{i} L^{i}$ terimi $y_{t+i}$ değişkeninin tepkisindeki yansımadır. $\mu_{i}$ etki çarpanlarının göstergesidir.

\section{TAHMIN SONUÇLARI}

Çalışmada ilk olarak serilerin durağanlıkları sınanmıştır. Durağanlık, öncelikle yapısal kırılmayı dikkate almayan ADF (Genişletilmiş Dickey ve Fuller), KPSS (Kwiatkowski, Phillips, Schmidt ve Shin) ve Dickey-Fuller GLS birim kök testlerine göre araştırılmıştır. Değişkenlere ait durağanlık test sonuçları Tablo 2'de verilmiştir.

Tablo 2: ADF, KPSS ve GLS Birim Kök Test Sonuçları

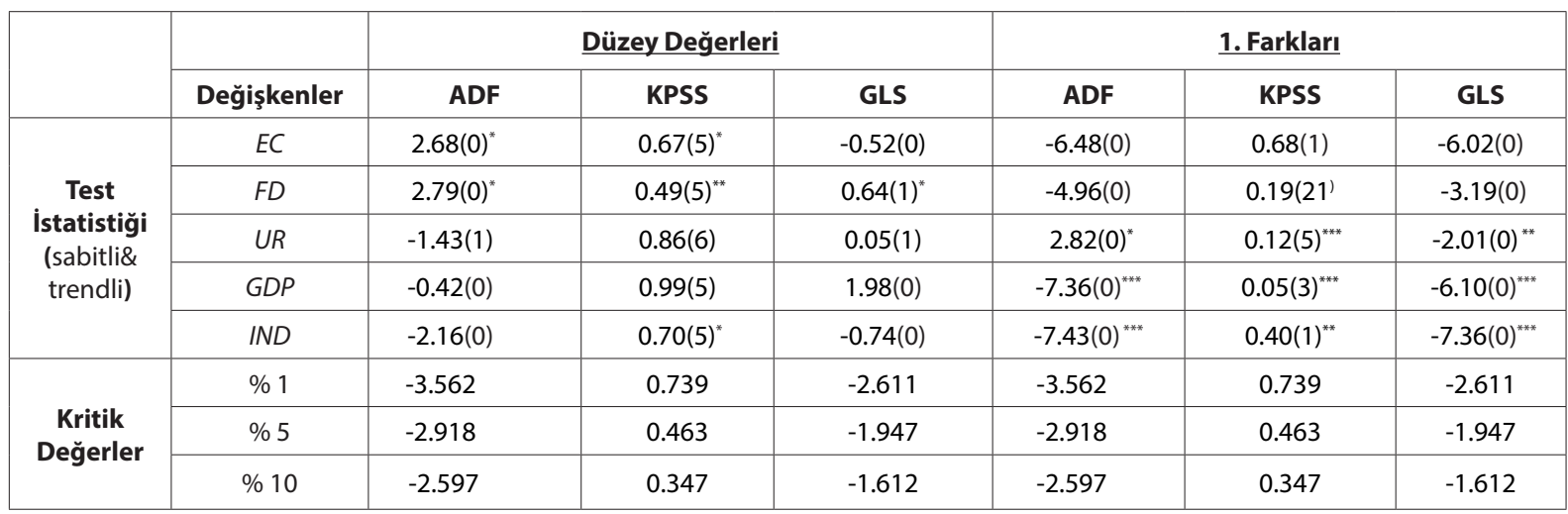

1-Parantez içindeki değerler ADF ve GLS için gecikme uzunluklarını, KPSS için bant genişliğini ifade etmektedir. Gecikme uzunluğunun seçiminde Schwarz Bilgi Kriteri (SIC) kullanılmıştır. Bant genişliği ise Bartlett Kernel modeli kullanılarak Newey-West göre belirlenmiştir.

2-ADF için \%1, \%5 ve \%10 önem düzeylerindeki MacKinnon (1996) kritik değerleridir. KPSS için \%1, \%5 ve \%10 önem düzeylerindeki Kwiatkowski-Phillips-Schmidt-Shin (1992) asimtotik kritik değerleridir. GLS için ise, \%1, \%5 ve \%10 önem düzeylerinde ElliottRothenberg-Stock (1996) tarafından geliștirilen kritik tablo değerleridir.

3- ${ }^{* * * * * *}$, ve" sırasıyla \%1, \%5 ve \%10 önem düzeylerinde anlamlılığı ifade etmektedir.

Tablo 2'ye göre enerji tüketimi ve finansal gelişme serileri seviye düzeylerinde $\% 10$ düzeyinde anlamlıdır. Dolayısıyla, bu iki değişken seviyede durağandır. Diğer üç değişken ise birinci farkları alındığında durağan hale geldiği görünmektedir. Bu yüzden, enerji tüketimi ve finansal gelişme değişkenleri $\mathrm{I}(0)$, kentleşme, sanayileşme ve ekonomik büyüme değişkenleri I(1)'dir.
ADF, KPSS ve GLS birim kök testleri analizlerde serilerde oluşan yapısal kırılmaları dikkate alamamaktadır. Bunun için serilerde birim kök sınaması yaparken seride beş yapısal kırılmaya izin veren ve Kapetanios (2002) tarafından geliştirilen birim kök testi de kullanılmıştır. Bu birim kök testinin sonuçları Tablo 3'de yer almaktadır.

Tablo 3: Çoklu Yapısal Kırılmalı Birim Kök Testi Sonuçları

\begin{tabular}{|l|c|c|c|c|c|}
\hline \multirow{2}{*}{ Değişkenler } & $\tau_{\text {min }}^{1}$ & $\tau_{\text {min }}^{2}$ & $\tau_{\min }^{3}$ & $\tau_{\min }^{4}$ & $\tau_{\min }^{5}$ \\
\hline $\mathrm{EC}$ & 3.6782 & 4.0397 & 4.0396 & 4.0397 & 4.0397 \\
\hline $\mathrm{UR}$ & 3.9784 & 2.4529 & 2.4529 & 2.4529 & 2.4529 \\
\hline $\mathrm{FD}$ & 3.1105 & 3.2805 & 3.2805 & 3.2805 & 3.2805 \\
\hline $\mathrm{GDP}$ & 3.9805 & 4.7097 & 4.7097 & 4.7097 & 4.7097 \\
\hline $\mathrm{IND}$ & 3.2434 & 3.3452 & 3.3452 & 3.3452 & 3.3452 \\
\hline$\Delta \mathrm{EC}$ & $7.3051^{* * *}$ & $8.3253^{* * *}$ & $8.3253^{* * *}$ & $8.3253^{* * *}$ & $8.3253^{* * *}$ \\
\hline$\Delta \mathrm{UR}$ & $6.2412^{* * *}$ & $10.5064^{* * *}$ & $12.6576^{* * *}$ & $12.1021^{* * *}$ & $11.1088^{* * *}$ \\
\hline$\Delta \mathrm{FD}$ & $5.2226^{* *}$ & $5.5088^{* *}$ & 5.8576 & 5.2226 & 5.5088 \\
\hline$\Delta \mathrm{GDP}$ & $5.2405^{* *}$ & $5.5354^{*}$ & 5.7893 & 6.2105 & 6.4590 \\
\hline$\Delta \mathrm{IND}$ & $8.2298^{* * *}$ & $8.1693^{* * *}$ & $8.1693^{* * *}$ & $8.1693^{* * *}$ & $8.1693^{* *}$ \\
\hline
\end{tabular}

$\tau_{\min }^{1}, \tau_{\min }^{2}, \tau_{\min }^{3} \tau_{\min }^{4} \tau_{\text {ve }}^{5} \tau_{\text {min }}^{5}$ sırasıyla bir, iki, üç, dört ve beş yapısal kırılmayı ifade etmektedir. ***, ** ve * sırasıyla \%1, \% 5 ve $\% 10$ düzeyinde anlamlııı̆ı ifade etmektedir. 
Tablo 3'de görüldüğü üzere, yapısal kırılmayı dikkate alan birim kök testine göre tüm serilerin düzey değerleri itibariyle birim kök içerdiğini ifade eden sıfır hipotezi reddedilmemektedir. Yani, değişkenler düzey değerleri itibariyle değil, birinci farkı alındığında durağan olduğu görülmektedir. Dolayısıyla, yapısal kırılmayı dikkate alan Kapetanios (2002) birim kök testine göre enerji tüketimi, kentleşme, sanayileşme, ekonomik büyüme ve finansal gelişme serileri I(1)'dir. Birinci fark serilerindeki yapısal kırıma sayıları enerji tüketimi, kentleşme ve sanayileşme için beş, finansal gelişme ve ekonomik büyüme serileri için iki oldu- ğu görülmektedir.

Durağanlık testleri yapıldıktan sonra, seriler arasında uzun dönem ilişkisi olup olmadığı çoklu yapısal kırılmaya izin veren Maki (2012) eşbütünleşme testiyle analiz edilmiştir. Enerji tüketiminin bağımlı değişken olduğu modelimiz aşağıdaki (8) nolu denklem şeklinde kurulmuştur:

$$
E C_{t}=\alpha_{0}+\alpha_{1} G D P_{t}+\alpha_{2} I N D_{t}+\alpha_{3} F D_{t}+\alpha_{4} U R_{t}+u_{t}
$$

$\mathrm{Bu}$ (8) nolu denklem Maki (2012) çoklu yapısal kırılma testiyle test edilmiş olup, elde edilen sonuçlar Tablo 4'te özetlenmektedir.

Tablo 4: Çoklu Yapısal Kırılmalı Eşbütünleşme Testi Sonuçları

\begin{tabular}{|l|c|c|c|c|c|}
\hline \multirow{2}{*}{ Modeller } & Test İstatistiği & $\mathbf{1 \%}$ & $\mathbf{5 \%}$ & $\mathbf{1 0 \%}$ & \multirow{2}{*}{ Yapısal Kırılma Tarihleri } \\
\cline { 3 - 5 } & $-9.5792^{* * *}$ & -6.856 & -6.306 & -6.039 & $1971,1986,1990,1994,2003$ \\
\hline Model 0 & $-9.5037^{* * *}$ & -7.053 & -6.494 & -6.220 & $1966,1971,1991,1994,2002$ \\
\hline Model 1 & $-10.6663^{* * *}$ & -9.441 & -8.869 & -8.541 & $1964,1971,1990,1996,2003$ \\
\hline Model 2 & $-11.2829^{* * *}$ & -10.08 & -9.482 & -9.151 & $1965,1971,1981,1990,2002$ \\
\hline
\end{tabular}

Kritik değerler, Maki (2012)'nin Tablo 1'deki kritik değerleridir. ***, \%1 önem düzeyinde eşbütünleşme ilişkisinin olduğunu ifade etmektedir.

Tablo 4'teki sonuçlara göre tüm modeller, bütün önem düzeylerinde istatistiki olarak anlamlıdır. Yani, yapısal kırılmayla birlikte eşbütünleşme olmadığını ifade eden sıfır hipotezi dört model için de reddedilmektedir. Başka bir ifadeyle, hesaplanan test istatistiklerinin, bütün önem düzeylerindeki kritik değerlerden küçük olduğu, dolayısıyla değişkenler (EC, GDP, FD, UR ve IND) arasında eşbütünleşme ilişkisinin mevcut ol- duğu belirlenmiştir. Ayrıca bu test yönteminin, Türkiye ekonomisindeki yapısal kırılma tarihlerini başarılı bir şekilde tespit ettiği görülmektedir.

Değişkenler arasında uzun dönemli ilişki bulunmasıyla eşbütünleşme vektör tahmincileri yoluyla katsayı tahminini mümkün olmaktadır. Bu bağlamda, DOLS ve FMOLS tahmincileriyle tahmin yapıldı ve tahmin sonuçları Tablo 5'te özetlenmiştir.

Tablo 5: DOLS ve FMOLS Tahmin Sonuçları

\begin{tabular}{|l|c|c|c|c|}
\hline & GDP & IND & UR & FD \\
\hline \multirow{2}{*}{ DOLS } & $1.8167^{* * *}$ & $0.0120^{* * *}$ & $0.0093^{* * *}$ & $0.0025^{*}$ \\
& $(5.2358)$ & $(-4.7560)$ & $(5.2636)$ & $(1.7597)$ \\
\hline \multirow{2}{*}{ FMOLS } & $1.7125^{* * *}$ & $0.0129^{* * *}$ & $0.0034^{* * *}$ & $0.0033^{*}$ \\
& $(7.9150)$ & $(-6.0465)$ & $(6.5957)$ & $(1.8138)$ \\
\hline
\end{tabular}

*** ve *, \% 1 ve \% 10 düzeyinde anlamlılığı ifade etmektedir. Gecikmeler ve öncüller DOLS tahmincisi için 1 olarak seçilmiştir.

Tablo 5 'teki DOLS ve FMOLS sonuçları incelendiğinde; ekonomik büyüme, sanayileşme, kentleşme ve finansal gelişme değişkenlerinin katsayıları hemen hemen bütün önem düzeylerinde istatistiksel olarak anlamlı ve işaretleri beklenildiği gibi pozitif olduğu görülmektedir. Dolayısıyla, Türkiye'de ekonomik büyüme, sanayileşme, kentleşme ve finansal gelişme arttıkça, enerji tüketiminin de artacağı söylenebilir.

Ancak katsayıların değerlerine baktığımızda, hem DOLS hem de FMOLS tahmin sonuçları Türkiye'deki enerji tüketimini etkileyen en önemli değişkenin ekonomik büyüme olduğunu ortaya koymaktadır. Mesela, Türkiye'de ekonomik büyümede meydana gelen \% $1^{\prime}$ lik artış, enerji tüketiminde \% 1.8 ile \% 1.7 arasında değişen bir artışa yol açtığı görülmektedir. İkinci en önemli etmen ise sanayileşme olduğu tespit edilmiştir. Türkiye'deki finansal gelişme ve kentleşmenin ise, enerji tüketimi üzerinde etkisinin daha az olduğu tespit edilmiştir. Son olarak, eşbütünleşme testi ve tahminci sonuçlarının güvenirliğini sınamak için SVAR modeline dayalı etki-tepki analizi yapılmıştır. Etki tepki fonksiyonlarl; rassal hata terimlerinden birindeki bir standart sapmalık şokun içsel değişkenlerin şimdiki ve gelecekteki değerlerine olan etkisini yansıtmakla birlikte, etkide bulunan değişkenin bir politika aracı olarak kullanılabilmesi konusunda fikir veren bir sistemdir (Yaylalı ve Lebe, 2011, s.39-40). Grafik 1'de analize konu olan değişkenlerin etki-tepki fonksiyonları sergilenmektedir. 
Response to Cholesky One S.D. Innovations
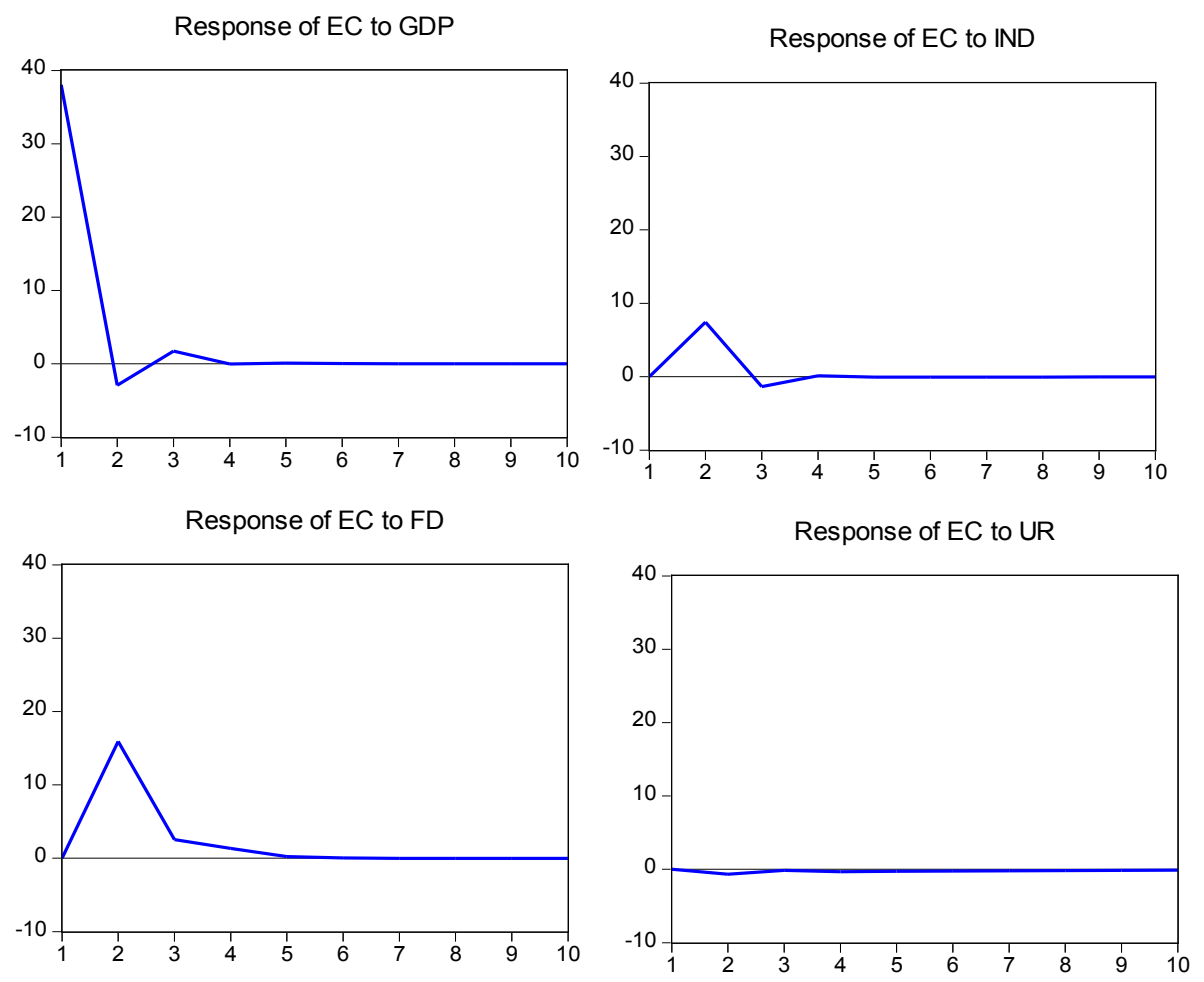

Grafik 1: Etki-Tepki Fonksiyonları

Grafik 1'e bakıldığında, ekonomik büyüme (GDP), sanayileşme (IND) ve finansal gelişme (FD) şokuna enerji tüketimi (EC) genelde pozitif yönde tepki verdiği görülmektedir. Kentleşme (UR) şoklarına ise, genellikle negatif yönde tepki verdiği ve bu tepkilerinin de çok düşük (neredeyse sıfır) olduğu söylenebilir. Dolayısıyla, ekonomik büyüme, sanayileşme ve finansal gelişmede görülen bir artışın, Türkiye'deki enerji tüketimini de arttıracağı belirlenmiştir. Şokların büyüklük anlamında etkileri genel olarak değerlendirildiğinde, özellikle ekonomik büyüme ile finansal gelişmenin Türkiye'deki enerji tüketimi üzerinde daha fazla etkilerinin olduğu ifade edilebilir.

\section{SONUÇ}

Bu çalışmada amaç, Türkiye'de ekonomik büyüme, finansal geliş̧me, sanayileşme ve kentleşmenin enerji tüketimi üzerindeki etkisini incelemektir. Bu bağlamda, ilk olarak bu değişkenlere ait serilerin durağanlıkları geleneksel ve yapısal kırılmaya izin veren birim kök testleriyle sınanmıştır. Bu testlerin sonucunda serilerin yapısal kırılmayla birlikte birim kök içerdiği ve durağanlık mertebesinin I(1) olduğu tespit edilmiştir. Serilerin I(1) olması üzerine Kapetanios (2002) tarafından geliştirilen ve beş yapısal kırılmaya izin veren eşbütünleşme testi yapılmıştır. Kapetanios (2002) testi sonucunda, seriler arasında uzun dönem ilişkisinin olduğu sonucuna ulaşılmıştır. Bununla birlikte bu test yönteminin, Türkiye ekonomisindeki yapısal kırılma tarihlerini başarılı bir şekilde tespit ettiği belirlenmiştir.

Son olarak, eşbütünleşme testinin güvenirliğini sınamak için model, DOLS ve FMOLS ile tahmin edilmiş ve SVAR modeline dayalı etki-tepki analizi yapılmıştır. DOLS, FMOLS ve SVAR analizi sonuçları genel olarak değerlendirildiğinde bulguların birbiriyle örtüştüğü görülmektedir. Bulgular, Türkiye'deki enerji tüketimi üzerinde etkili olan ekonomik büyüme, sanayileşme ve finansal gelişmenin öne çıktığını ortaya koymaktadır. Özellikle ekonomik büyümenin diğer etmenlere göre daha büyük bir rol oynadığı, ancak kentleşmenin fazla bir etkisinin olmadığı belirlenmiştir. Bu yönüyle çalışmamız Shahbaz ve Lean (2012 çalışmasıyla farklılık gösterir iken, Al-mulali ve Lee (2013) ve Khan, Khan, Zaman ve Arif (2014) çalışmalarıyla büyük ölçüde benzerlik göstermektedir.

Sonuç olarak, Türkiye'deki ekonomik büyüme, finansal gelişme, kentleşme ve sanayileşmenin enerji tüketimi üzerinde etkili olduğu anlaşılmaktadır. Özellikle ekonomik büyümenin enerji tüketimim üzerindeki etkisi diğer değişkenlere göre oldukça yüksektir. Dolayısıyla politika yapıcılarının enerji tasarrufuna yönelik politikaları ekonomik büyümeyi negatif yönde değil, aksine pozitif yönde etkilemektedir. Türkiye 
enerji tüketiminde dışa bağımlılığı yüksek ve enerji ithalatçısı konumunda olan bir ülkedir. Türkiye'nin kısa dönemde enerji üretim kaynaklarını artırıp, bağımlılığını azaltması olanaksız görülmektedir. Dolayısıyla, politika yapıcılarının kısa dönemde enerji tasarrufuna yönelik politikalara yönelmeleri, uzun dönemde ise alternatif enerji kaynaklarına yönelik politikaları uygulaması Türkiye'nin enerji bağımlılığını azaltacağı düşünülmektedir.

\section{SON NOTLAR}

*Bu çalışma, 15. Uluslararası Ekonometri, Yöneylem Araştırması ve İstatistik Sempozyumu'nda (22-25 Mayıs 2014, Isparta/Türkiye) sunulan bildirinin gözden geçirilip, genişletilmiş versiyonudur.

${ }^{1} \mathrm{Bu}$ gruba giren çalışmalar ile ilgili literatür için Ozturk (2010) çalışmasına bakınız.

${ }^{2}$ Bazı çalışmalar enerji tüketimi yerine elektrik tüketimi esas aldıkları görülmektedir (Tang ve Shahbaz, 2011; Solarin ve Shahbaz, 2013).

\section{KAYNAKLAR}

Akbaş, Y.E. ve Şentürk, M. (2013). "MENA Ülkelerinde Elektrik Tüketimi İle Ekonomik Büyüme Arasındaki Karşılıklı İlişkinin Analizi” Erciyes Üniversitesi İktisadi ve İdari Bilimler Fakültesi Dergisi, 41: 45-67.

Al-Mulali, U. and Lee, J.Y.M. (2013). "Estimating the impact of the financial development on energy consumption: Evidence from the GCC (Gulf Cooperation Council) countries", Energy, 60: 215-221

Bagehot, W. (1873). Lombart street: A Description of the Money Market, Edward Payson Dutton and Company, New York (Reprint 1920).

Bai, J. and Perron, P. (1998). "Estimating and testing linear models with multiple structural changes" Econometrica, 66: 47-78.

Çoban, S. and Topcu, M. (2013). "The nexus between financial development and energy consumption in the EU: A dynamic panel data analysis" Energy Economics, 39: 81-88.

Elliott, G., Rothenberg, T.J. and Stock, J.H. (1996). "Efficient tests for an autoregressive unit root" Econometrica, 64: 813-836.

Enders, W. (1995). Applied Econometric Time Series, $1^{\text {st }}$ Ed., New York: Wiley.

Goldsmith, R.W. (1969). Financial Structure and Economic Development, Yale University Press, New Haven.

Göçer, İ., Mercan, M. ve Peker, O. (2013). "Kredi hacmi artışının cari açı̆̆a etkisi: Çoklu yapısal kırılmalı eşbütünleşme analizi” Ekonometri ve İstatistik, 18: 1-17.

Gregory, A.W. and Hansen, B.E. (1996). "Residualbased tests for cointegration in models with regime shifts" Journal of Econometrics, 70(1): 99-126.
Gujarati, D.N. (1999). Basic Econometrics, $3^{\text {rd }}$ Edition, Mc Graw Hill.

Hatemi-J, A. (2008). "Tests for cointegration with two unknown regime shifts with an application to financial market integration" Empirical Economics, 35: 497505.

Holtemöller, O. (2002). "Structural vector autoregressive models and monetary policy analysis", Discussion Papers, Interdisciplinary Research Project 373: Quantification and Simulation of Economic Processes, No. 2002,7 .

Islam, F., Shahbaz, M., Ahmed, A.U. and Alam, M.M. (2013). "Financial development and energy consumption nexus in Malaysia: a multivariate time series analysis" Economic Modelling, 30: 435-441.

Jalil, A. and Feridun, M. (2011). "The impact of growth, energy and financial development on the environment in China: A cointegration analysis" Energy Economics, 33: 284-291.

Kapetanios, G. (2002), "Unit root testing against the alternative hypothesis of up to $m$ structural breaks" Working Papers, No.469.

Khan, M.A., Khan, Z.K., Zaman, K. and Arif, M. (2014). "Global estimates of energy-growth nexus: Application of seemingly unrelated regressions" Renewable and Sustainable Energy Reviews, 29: 63-71.

Khan, M.A., Khan, Z.K., Zaman, K., Irfan, D. and Khatab, H. (2014). "Questing the three key growth determinants: Energy consumption, foreign direct investment and financial development in South Asia" Renewable Energy, 68: 203-215.

Lumsdaine, R.L. and Papell, D.H. (1997). "Multiple trend breaks and the unit-root hypothesis" The Review of Economics and Statistics, 79(2): 212-218.

Mackinnon, J.G. (1996). "Numerical distribution functions for unit root and cointegration tests" Journal of Applied Econometrics, 11: 601-618.

Maki, D. (2012). "Tests for cointegration allowing for an unknown number of breaks" Economic Modelling, 29(5): 2011-2015.

McCoy, D. (1997). "How useful is structural VAR analysis for Irish economics", Research Technical Papers, No.2/RT/97.

Mckinnon, R.I. (1973). Money and Capital in Economic Development, The Brookings Institution, Washington, DC.

Mudakkar, S.R., Zaman, K., Shakir, H., Arif, M., Naseem, I. and Naz, L. (2013). "Determinants of energy consumption function in SAARC countries: Balancing the odds", Renewable and Sustainable Energy Reviews, 28: 566-574. 
Ozturk, I. (2010). "A literature survey on energygrowth nexus", Energy Policy, 38, 340-349.

Ozturk, I. and Acaravci (2013). "The long-run and causal analysis of energy, growth, openness and financial development on carbon emissions in Turkey", Energy Economics, 36: 262-267.

Pao, H.-T. and Tsai, C.-M. (2011). "Multivariate Granger causality between $\mathrm{CO} 2$ emissions, energy consumption, FDI (foreign direct investment) and GDP (gross domestic product): Evidence from a panel of BRIC (Brazil, Russian Federation, India, and China) countries" Energy, 36: 685-693.

Pedroni, P. (2000). "Fully modified OLS for heterogeneous cointegrated panels" Advances in Econometrics, 15: 93-130.

Phillips, P.C.B. and Hansen, B.E. (1990). "Statistical inference in instrumental variables regressions with $I(1)$ processes" Review of Economic Studies, 57(1): 99-125.

Sadorsky, P. (2010). "The impact of financial development on energy consumption in emerging economies" Energy Policy, 38: 2528-2535.

Sadorsky, P. (2011). "Financial development and energy consumption in Central and Eastern European frontier economies" Energy Policy, 39: 999-1006.

Schumpeter, J.A. (1911). The Theory of Economic Development. Harvard University Press, Cambridge (Reprinted 1969).

Shahbaz, M. and Lean, H.H. (2012). "Does financial development increase energy consumption? the role of industrialization and urbanization in Tunisia" Energy Policy, 40: 473-479.

Shahbaz, M., Hye, Q.M.A., Tiwari, A.K. and Leitão, N.C. (2013). "Economic growth, energy consumption, financial development, international trade and $\mathrm{CO}_{2}$ emissions in Indonesia" Renewable and Sustainable Energy Reviews, 25: 109-121.

Shahbaz, M., Khan, S. and Tahir, M.I. (2013). “The dynamic links between energy consumption, economic growth, financial development and trade in China: Fresh evidence from multivariate framework analysis" Energy Economics, 40: 8-21.
Shahbaz, M., Mutascu, M. and Azim, P. (2013). "Environmental Kuznets curve in Romania and the role of energy consumption" Renewable and Sustainable Energy Reviews, 18: 165-173.

Shahbaz, M., Solarin, S.A., Mahmood, H. and Arouri, M. (2013). "Does financial development reduce $\mathrm{CO}_{2}$ emissions in Malaysian economy? A time series analysis" Economic Modelling, 35: 145-152.

Shahbaz, M., Tiwari, A.K. and Nasir, M. (2013). "The effectsof financial development, economic growth, coal consumption and trade openness on $\mathrm{CO} 2$ emissions in South Africa" Energy Policy, 61: 1452-1459.

Shahbaz, M., Uddin, G.S., Rehman, I.U. and Imran, K. (2014). "Industrialization, electricity consumptionand $\mathrm{CO}_{2}$ emissions in Bangladesh" Renewable and Sustainable Energy Reviews, 31: 575-586.

Shaw, E.S. (1973). Financial Deepening in Economic Development, Oxford University Press, New York.

Solarin, S.A. and Shahbaz, M. (2013). "Trivariate causality between economic growth, urbanisation and electricity consumption in Angola: Cointegration and causality analysis" Energy Policy, 60: 876-884.

Stock, J. and Watson, M.W. (1993). "A simple estimator of cointegrating vectors in higher order integrated systems", Econometrica, 61(4): 783-820.

Tang, C.F. and Shahbaz, M. (2011). "Revisiting the Electricity Consumption-Growth Nexus for Portugal: Evidence from a Multivariate Framework Analysis" MPRA Paper, no.28393.

Yaylalı, M. ve Lebe, F. (2011). "Beşeri Sermaye ile İktisadi Büyüme Arasındaki İlişkinin Ampirik Analizi” Marmara Üniversitesi İIBF Dergisi, XXX(I): 23-51.

Zhang, Y.-J., Fan, J.-L. and Chang, H.-R. (2011). "Impact of China's stock market development on energy consumption: An empirical analysis" Energy Procedia, 5: 1927-1931.

Zivot, E. and Andrews, D.W.K. (1992). "Furtheer vidence on the great crash, the oil-price shock, and the unit-root hypothesis" Journal of Business and Economic Statistics, 10(3): 251-270. 